\title{
Preface to the Special Issue on "Recent Advances in Welding Met- allurgy"
}

\author{
Fukuhisa MATSUDA \\ Welding Research Institute, Osaka University, Mihogaoka, Ibaraki, Osaka-fu, 567 Japan.
}

"Welding" nowadays is widely and practically used in various industrial fields as the fundamental technology for the assembly of lots of products. Therefore, at the present time when the industrial fields have been widened and diversified, the practical application of welding technology is further increased. Furthermore, the social demands for high quality, high reliability, high efficiency and low price of products have recently become stronger year after year, to keep up the trend of increasing demands for the further development of welding technology.

The field of welding technology can generally and roughly be classified into four categories such as welding material, welding heat source (equipment), weld performance, and evaluation of weld reliability, and both research and technological development to comply with the social needs are now in significant progress in respective technical fields.

As for the material field of welding, new ceramic materials, composite materials, high integrated semiconductive materials, etc., are produced because of the recent development of materials, and high welding technology for both similar and dissimilar materials to the above is required. Furthermore, as for the conventional steel and metallic materials, new materials of high quality and high reliability have been developed one after another, and the development of new welding technology for them is desired and expected. Since the advanced metallurgical knowledge of materials for the purpose of welding is required in order to improve and develop the welding technology, both study and research on welding from the point of materials have always and continuously been carried out. Therefore, both periodic exchange and communication of technical information on the latest technological development are required and essential on a global scale.

Based on the purport above, this special issue is devoted to the recent research and development of welding metallurgy and materials science. With sincere appreciation to the efforts by the authors and the persons $\&$ parties concerned, further development in future based on this issue is expected. 